\title{
The Prevalence of High Blood Pressure and Its Relationship with Sociodemographic, Anthropometric and Lifestyles Indicators: A Population-Based Study in Aplahoue Health District, Benin
}

\author{
Azandjeme Colette ${ }^{1}$, Sossa Jerome Charles ${ }^{1, *}$, Kandissounon Rosemonde ${ }^{1}$, Patrick Makoutode ${ }^{2}$, \\ Sopoh E. Ghislain ${ }^{3}$, Noël M. Paraïso ${ }^{1}$, Glele Ahanhanzo Yolaine ${ }^{4}$, Ouendo Edgard-Marius ${ }^{2}$ \\ ${ }^{1}$ Department of Health Promotion, University of Abomey-Calavi, Benin \\ ${ }^{2}$ Department of Policies and Health Systems, University of Abomey-Calavi, Benin \\ ${ }^{3}$ Department of Health and Environment, University of Abomey-Calavi, Benin \\ ${ }^{4}$ Department of Epidemiology and Biostatistics, University of Abomey-Calavi, Benin
}

Received August 12, 2019; Revised December 24, 2019;Accepted December 30, 2019

Copyright $\odot 2020$ by authors, all rights reserved. Authors agree that this article remains permanently open access under the terms of the Creative Commons Attribution License 4.0 International License

\begin{abstract}
High blood pressure (HBP) is a public health problem with high prevalence and serious medical consequences. The objective of this study was to determine the prevalence of high blood pressure and its associated factors in adults aged 25 to 64 in the health district of Aplahoué in Benin. This was a cross-sectional study carried out in 2016. The study involved 540 participants randomly selected by cluster sampling techniques. A questionnaire was used to collect data on dietary patterns, lifestyles and socio-economic conditions. The multivariate logistic regression model was used to identify factors associated with HBP. The median age of participants was 40 years old with an interquartile range of [32-51.5] years. Mean systolic and diastolic blood pressure were $133.56 \pm 20.68$ and $83.26 \pm 13.29 \mathrm{mmHg}$, respectively. The prevalence of HBP was $29.94 \%$. The urban environment, the high frequency of salt consumption, the low frequency of fruit and vegetable consumption, the habit of smoking, physical inactivity, and being overweight were found to increase the risk of HBP. Interventions to promote healthy lifestyles are timely in the health district of Aplahoué.
\end{abstract}

Keywords High Blood Pressure, Prevalence, Determinants, Adult, Benin

\section{Introduction}

Noncommunicable Diseases (NCDs) are a rising epidemic worldwide. According to the World Health Organization (WHO), in 2016, NCDs were responsible for 40.5 million or $71 \%$ of global deaths [1]. The main NCDs include cardiovascular diseases, cancers, diabetes, and chronic lung diseases. In 2017, 3 million deaths globally were attributed to high blood pressure (HBP) [1]. Most of these deaths $(80 \%)$ occurred in low- and middle-income countries $[2,3]$. More than a quarter $(26.4 \%)$ of the global adult population is hypertensive and if no countermeasures will be taken, this proportion will reach $29.2 \%$ by 2025 . In addition, nearly $75 \%$ of these patients will live in developing countries $[4,5]$. In Benin, the prevalence of HBP was $27.5 \%$ [6]. HBP has a significant negative impact on the economy of African countries, ranging from high medical costs to decreased productivity, both at the individual and national levels [4, 7]. In the context of limited resources in low-income countries, primary prevention remains the best solution against HBP, like other NCDs, which require long-term and expensive treatment [8].

To reduce the incidence rate of cardiovascular disease and its consequences, it is necessary to control HBP by averting its modifiable risk factors. In the health district of Aplahoue located in the Couffo department in Benin, the prevalence of hypertension was $29.6 \%$, according to the WHO STEPS survey carried out in 2008 [5]. The objective was to determine the prevalence of HBP and its associated factors in adults aged 25 to 64 in the health district of Aplahoué in Benin. 


\section{Subjects and Methods}

\subsection{Setting}

Aplahoué health district is located in the Couffo department, in southern Benin. The total population of the health district was estimated to comprise 420914 inhabitants in 2014, according to the projections of the National Institute of Statistics and Economic Analysis of Benin [9]. At the community level, no NCD control activities are included in the annual work plan of the health district.

\subsection{Population and Study Design}

This was a cross-sectional study carried out from May to July 2016 . The study population included adults aged 25 to 64 living in the health district of Aplahoué.

\subsection{Sampling Methods}

The minimum sample size was estimated to be 481 participants using Shwartz formula and assuming the risk of error $\alpha$ of $5 \%$, and a precision of $5 \%$, based on the prevalence of hypertension in the department of Couffo $(29.6 \%)$ [5]. Subjects were randomly selected by the adapted World Health Organization cluster sampling technique. A sample of 540 subjects participated in the study.

\subsection{Variables}

The dependent variable was HBP. We made two measurement in the sitting position on the left arm; the first after 10 minutes of rest and the second 5 minutes after the first reading. We then used the average of the two measures. An adult was considered having HBP if he was under antihypertensive medical treatment or had at least one of the following statements:

- $\quad$ Systolic blood pressure greater than or equal to 140 $\mathrm{mmHg}$ (TAS $\geq 140 \mathrm{mmHg}$ );

- Diastolic blood pressure greater than or equal to 90 $\mathrm{mmHg}(\mathrm{TAD} \geq 90 \mathrm{mmHg}$ );

- $\quad$ Systolic blood pressure greater than or equal to 140 and diastolic blood pressure greater than or equal to $90 \mathrm{mmHg}$ (TAS $\geq 140$ and $\mathrm{TAD} \geq 90 \mathrm{mmHg}$ );

The independent variables included:

- Demographic, socio-economic and cultural factors: age, sex, occupation, educational level, ethnicity, marital status, place of residence, knowledge of HTA, socio-economic level. The socio-economic level was assessed on the basis of household ownership scores. Subjects were classified into three terciles: poor, middle and rich.
- Behavioral factors: salt intake, fat consumption, alcohol consumption, fruit and vegetable consumption, smoking, physical activity.

- Biological factors: family history of hypertension, overweight, obesity.

- health factors: the history of pre-eclampsia and oral contraception in women.

Salt consumption was appreciated through the weekly consumption of frequency of canned foods; salted meats; salted fermented "néré" seeds; broths (Maggi) and adding salt to food on the table.

Consumption of fruits and vegetable was assessed through the intake of at least five servings of fruits and vegetables according to the portions of the Beninese food guide [10]

Alcohol consumption was defined by the frequency and amount of consumption. Thus, the consumption was considered abusive when the respondent consumed alcohol for at least 4 days out of 7 days of a week ( $\geq 4$ days per week). One consumption referred to 20 grams of alcohol per day in men and 10 grams per day for women, the amount of alcohol was determined from the following formula: $\mathrm{Q}=$ Alcohol content $\times$ Volume consumed in liters $\times$ Density of alcohol (with alcohol density $=0.8$ ) [11].

Dietary intake of high saturated fat was defined by the frequency of saturated fat source diet consumption (coconut oil, palm oil, fried foods, butter and red meat).

Physical activity was assessed using the Metabolic Equivalent of Task (MET) with reference to the WHO guidelines for chronic diseases prevention [12] Thus, we distinguished two groups of individuals: active ( $\geq 3$ MET, $\geq 30 \mathrm{~min} / \mathrm{d}$ ) and inactive ( $\geq 3 \mathrm{MET},<30 \mathrm{~min} /$ day or $<3$ MET, regardless of duration).

Overweight and obesity were assessed by the body mass index (BMI).

\subsection{Data Collection}

Data were collected through individual interviews using a questionnaire. Measurements of blood pressure, weight and height were recorded using an electronic sphygmomanometer, scales and measuring board by trained students, respectively.

\subsection{Ethical Considerations}

The objective of the study was explained to the participants. Voluntary informed oral consent was obtained from each participating before starting the interview and measurements. This consent claims that participants were not at risk by refusing to participate in the survey or stopping their collaboration during the study in any way prior to commencing the interview. 


\subsection{Data Analysis}

Data were analyzed using the STATA 11 software. Pearson's Chi-square test was performed to search for associations between the dependent variable and the independent variables in the univariate analysis at the significance level $\mathrm{p}<0.20$. The multiple logistic regression model includes the variables significantly associated with HBP in the univariate analysis. The threshold of significance was set at $\mathrm{p}<0.05$. No missing value was noted.

\section{Results}

\subsection{Sociodemographic and Lifestyles Characteristics}

Of the 540 participants, $53.03 \%$ were men. The median age of the respondents was 40 years with an interquartile range of $[32 ; 51.5]$ years, subjects aged 25 to 34 accounted for $32.36 \%, 57.31 \%$ of participants never went to school, $75.20 \%$ lived in rural areas and $37.95 \%$ were farmers. In addition, $55.88 \%$ of the respondents knew at least 2 consequences of HBP.

Among the surveyed participants , 38.23\% were found to consume sutured fat food at least seven times a week, $21.44 \%$ consumed less than five servings of fruits and vegetables a day, and $6.93 \%$ used to have heavy alcohol drinking ( $\geq 4$ days / week). In addition, $16.64 \%$ of the participants used to have tobacco and $28.96 \%$ were observed to be inactive. The family history of hypertension was found in $30.85 \%$ of subjects, while $18.98 \%$ and $14.04 \%$ were overweight and obese, respectively.

\subsection{Prevalence of High Blood Pressure}

The mean systolic blood pressure and diastolic blood pressure were $133.56 \pm 20.68 \mathrm{mmHg}$ and $83.26 \pm 13.29$ $\mathrm{mmHg}$, respectively. Out of all the participants, 154 (29.94\%; 95\% CI [26.84, 33.04]) showed HBP.

\subsection{Factors Associated with High Blood Pressure}

\subsubsection{Univariate Analysis}

Among sociodemographic factors, age, occupation, place of residence and economic status of participants were significantly associated with high blood pressure (Table 1).

The main health factors associated with HBP was pre-eclampsia in women.

The family history of hypertension as well as being overweight and obese were biological factors statistically associated with HBP (Table 2).

Behavioral factors associated with HBP were salt intake, fruit and vegetable consumption, alcohol consumption, smoking, and physical activity (Table 3). 
The Prevalence of High Blood Pressure and Its Relationship with Sociodemographic,

Anthropometric and Lifestyles Indicators: A Population-Based Study in Aplahoue Health District, Benin

Table 1. Sociodemographic, economic and cultural factors associated with HBP in adults aged 25 to 64 in the Aplahoué health district in Benin in 2015 , univariate analysis $(\mathrm{N}=540)$

\begin{tabular}{|c|c|c|c|c|c|}
\hline \multirow{2}{*}{ Variables } & \multicolumn{5}{|c|}{ High blood pressure $(n=154)$} \\
\hline & $\mathbf{n}$ & $\%$ & OR & $95 \%$ IC & p-value \\
\hline Age (years) & & & & & $<0.001$ \\
\hline $25-34$ & 18 & 11.43 & 1 & & \\
\hline $35-44$ & 34 & 23.40 & 2.36 & {$[0.85 ; 6.53]$} & \\
\hline $45-54$ & 46 & 44.42 & 6.19 & {$[2.54 ; 15.04]$} & \\
\hline $55-64$ & 56 & 55.75 & 9.75 & {$[3.56 ; 26.71]$} & \\
\hline Gender & & & & & 0.1845 \\
\hline Men & 89 & 33.40 & 1 & & \\
\hline Women & 65 & 26.04 & 0.70 & {$[0.41 ; 1.19]$} & \\
\hline Ethnic groups & & & & & 0.8289 \\
\hline Adja & 151 & 30.04 & 1 & & \\
\hline Fon/Mina/Yoruba & 3 & 26.37 & 0.83 & {$[0.15 ; 4.56]$} & \\
\hline Marital status & & & & & 0.2445 \\
\hline Single & 4 & 15.69 & 1 & & \\
\hline Married & 142 & 30.83 & 2.39 & {$[0.77 ; 7.42]$} & \\
\hline Divorced/widowed & 8 & 28.25 & 2. 11 & {$[0.34 ; 12.90]$} & \\
\hline Education & & & & & 0.3174 \\
\hline No schooling & 94 & 31.89 & 1 & & \\
\hline Primary & 25 & 24.02 & 0.67 & {$[0.32-1.42]$} & \\
\hline Secondary & 28 & 28.16 & 0.83 & {$[0.43-1.61]$} & \\
\hline University & 7 & 41.35 & 1.50 & {$[0.75-2.99]$} & \\
\hline Occupation & & & & & $<0.001$ \\
\hline Employee & 16 & 46.22 & 1 & & \\
\hline Farmer & 42 & 19.46 & 0.28 & {$[0.11 ; 0.67]$} & \\
\hline Trader/seller & 53 & 42.62 & 0.86 & {$[0.39 ; 1.90]$} & \\
\hline Artisan & 21 & 21.13 & 0.31 & {$[0.15 ; 0.62]$} & \\
\hline Housewives & 9 & 37.21 & 0.68 & {$[0.15 ; 3.03]$} & \\
\hline Retired/unemployed/others & 13 & 43.99 & 0.91 & {$[0.31 ; 2.61]$} & \\
\hline Place of residence & & & & & 0.0055 \\
\hline Rural & 114 & 27.61 & 1 & & \\
\hline Urban & 40 & 37.01 & 1.54 & {$[1.14 ; 2.06]$} & \\
\hline Socio-economic level & & & & & 0.0047 \\
\hline Tercile 1 (poor) & 46 & 22.98 & 1 & & \\
\hline Tercile 1 & 57 & 28.07 & 1.30 & {$[0.64 ; 2.63]$} & \\
\hline Tercile 1 (rich) & 51 & 42.37 & 2.46 & {$[1.40 ; 4.33]$} & \\
\hline Knowledge on HPB & & & & & 0.6669 \\
\hline No consequence of HBP & 10 & 26.47 & 1 & & \\
\hline At least on consequence of HBP & 144 & 30.21 & 1.20 & {$[0.50 ; 2.86]$} & \\
\hline
\end{tabular}


Table 2. Health and biological factors associated HBP in adults aged 25 to 64 in the health district of Aplahoué in Benin in 2015, univariate analysis, $(\mathrm{N}=540)$

\begin{tabular}{|c|c|c|c|c|c|}
\hline \multirow{2}{*}{ Variables } & \multicolumn{5}{|c|}{ High blood pressure $(n=154)$} \\
\hline & $\mathbf{n}$ & $\%$ & OR & $95 \%$ IC & p-value \\
\hline \multicolumn{6}{|l|}{ Health factors } \\
\hline History of pre-eclampsia* & & & & & 0.0015 \\
\hline No & 47 & 21.69 & 1 & & \\
\hline Yes & 18 & 55.32 & 4.46 & {$[1.86 ; 10.70]$} & \\
\hline Oral contraceptives use* & & & & & 0.2227 \\
\hline No & 57 & 25.30 & 1 & & \\
\hline Yes & 8 & 34.22 & 1.53 & {$[0.75 ; 3.10]$} & \\
\hline \multicolumn{6}{|l|}{ Biological factors } \\
\hline Family history of HBP & & & & & $<0.001$ \\
\hline No & 69 & 19.16 & 1 & & \\
\hline Yes & 85 & 54.09 & 4.96 & {$[2.67 ; 9.22]$} & \\
\hline Overweight or obesity & & & & & $<0.001$ \\
\hline No & 111 & 27.48 & 1 & & \\
\hline Yes & 43 & 40.46 & 6.36 & {$[3.56 ; 11.34]$} & \\
\hline
\end{tabular}

* History of pre-eclampsia and oral contraceptive is belong to female individuals only ( $\mathrm{n}=65$ ).

Table 3. Nutritional and lifestyle factors associated with high blood pressure in adults aged 25 to 64 in the Aplahoué health district in Benin in 2015, univariate analysis, $(\mathrm{N}=540)$

\begin{tabular}{|c|c|c|c|c|c|}
\hline \multirow{2}{*}{ Variables } & \multicolumn{5}{|c|}{ High blood pressure $(n=154)$} \\
\hline & $\mathbf{n}$ & $\%$ & OR & $95 \%$ IC & p-value \\
\hline Frequency of salt consumption & & & & & $<0.001$ \\
\hline$<7$ times/week & 34 & 16.54 & 1 & & \\
\hline$\geq 7$ times/week & 120 & 39.98 & 3.35 & {$[2.22-5.06]$} & \\
\hline $\begin{array}{l}\text { Frequency of saturated fat-rich } \\
\text { food consumption }\end{array}$ & & & & & 0.0091 \\
\hline$<7$ times/week & 80 & 25.07 & 1 & & \\
\hline$\geq 7$ times/week & 74 & 39.81 & 1.81 & {$[1.17-2.81]$} & \\
\hline $\begin{array}{c}\text { Frequency of consumption of } \\
\text { fruits and vegetables }\end{array}$ & & & & & $<0.001$ \\
\hline$<7$ days/week & 50 & 69.87 & 1 & & \\
\hline 7 days/week & 104 & 23.25 & 0.13 & {$[0.07-0.22]$} & \\
\hline $\begin{array}{c}\text { Portions of fruits and vegetables } \\
\text { consumed }\end{array}$ & & & & & 0.3484 \\
\hline$<5$ portions/day & 35 & 33.02 & 1 & & \\
\hline$\geq 5$ portions/day & 119 & 29.10 & 0.83 & {$[0.56 ; 1.23]$} & \\
\hline Frequency of alcohol consumption & & & & & 0.0002 \\
\hline Never & 26 & 21.11 & 1 & & \\
\hline$<4$ days/week & 102 & 29.30 & 1.54 & {$[0.69 ; 3.45]$} & \\
\hline$\geq 4$ days/week & 26 & 69.98 & 8.70 & {$[3.53 ; 21.43]$} & \\
\hline Quantity of alcohol consumed & & & & & 0.0697 \\
\hline Zero & 26 & 21.11 & 1 & & \\
\hline Acceptable & 19 & 25.67 & 1.29 & {$[0.49 ; 3.34]$} & \\
\hline Excessive & 109 & 34.95 & 2.00 & {$[0.97 ; 4.12]$} & \\
\hline Tobacco use & & & & & $<0.001$ \\
\hline No & 102 & 23.42 & 1 & & \\
\hline Yes & 52 & 62.60 & 4.40 & {$[2.76 ; 7.03]$} & \\
\hline Physical activity & & & & & $<0.001$ \\
\hline Active & 49 & 13.91 & 1 & & \\
\hline Inactive & 105 & 69.26 & 13.93 & {$[6.39 ; 30.37]$} & \\
\hline
\end{tabular}


Table 4. Factors associated with high blood pressure in adults aged 25 to 64 in the Aplahoué health district in Benin in 2015, multivariate analysis, $(\mathrm{N}=540)$

\begin{tabular}{|c|c|c|c|}
\hline Variables & OR & $95 \%$ IC & p-value \\
\hline \multicolumn{4}{|l|}{ Place of residence } \\
\hline Rural & 1 & & \\
\hline Urban & 2.13 & {$[1.19 ; 3.80]$} & 0.012 \\
\hline \multicolumn{4}{|c|}{ Frequency of salt consumption } \\
\hline$<7$ times/week & 1 & & \\
\hline$\geq 7$ times/week & 3.40 & {$[1.76 ; 6.56]$} & 0.001 \\
\hline \multicolumn{4}{|c|}{ Frequency of consumption of fruits and vegetables } \\
\hline$<7$ days/week & 1 & & \\
\hline 7 days/week & 9.37 & {$[4.17 ; 21.06]$} & $<0.001$ \\
\hline \multicolumn{4}{|l|}{ Tobacco use } \\
\hline No & 1 & & \\
\hline Yes & 5.36 & {$[2.54 ; 11.29]$} & $<0.001$ \\
\hline \multicolumn{4}{|l|}{ Physical activity } \\
\hline Active & 1 & & \\
\hline Inactive & 11.30 & {$[4.98 ; 25.63]$} & $<0.001$ \\
\hline \multicolumn{4}{|c|}{ Overweight or obesity } \\
\hline No & 1 & & \\
\hline Yes & 4.81 & {$[2.56 ; 9.03]$} & $<0.001$ \\
\hline
\end{tabular}

\subsubsection{Multivariate Analysis}

The final logistic regression model showed that urbanization, salt intake, fruit and vegetable consumption, smoking, physical activity, overweight and obesity were significantly associated with HBP as shown in Table 4.

\section{Discussion}

The study examined factors associated with HBP in adults aged 25 to 64 years old in Aplahoué health district in Benin. The prevalence of HBP was 29.94\%. Urbanization, salt intake, fruit and vegetable consumption, physical activity, smoking, and being overweight were associated with HBP in adults aged 25 to 64 in this health district.

\subsection{Urbanization}

The higher risk of HBP in urban areas compared to rural areas has been reported in several studies that highlighted the effects of the living environment on the occurrence of HBP. According to Abebe et al., in Ethiopia in 2015, people living in urban areas were found to be $3.25(95 \% \mathrm{CI}=[1.67,6.29])$ times more likely to become hypertensive than those living in rural areas [13]. These differences between rural and urban areas also illustrate the overall negative impact of the current nutrition transition in urban areas district characterized by ready to eat street food known to be rich in fat and salt content [14].

\subsection{Salt Consumption}

The risk of HBP was high in individuals who consumed salt very often. This confirms the results of studies that reported an increase in blood pressure associated with excess salt intake. For example, in a 2013 Swiss population study, excessive mean salt intake correlated with HBP [15]. Similarly, the INTERSALT study, which examined the relationship between salt intake (measured in $24 \mathrm{~h}$ urine collections) and blood pressure in 52 centers around the world, found that a change of $100 \mathrm{mEq} /$ day of sodium consumption corresponded to a change of 3-6 $\mathrm{mmHg}$ systolic blood pressure values [16].

\subsection{Fruits and Vegetable Consumption}

Sufficient consumption of fruit and vegetables protects against HBP. Studies have shown the important role played by the antioxidants contained in fruits and vegetables (carotenoids, polyphenols and other antioxidant compounds) against inflammation that leads to arteriosclerosis. Stewart de Ramirez et al., in their study conducted on the population of sub-Saharan African countries (Malawi, Rwanda, Tanzania) found that the high frequency of fruit and vegetable consumption was significantly associated with lower systolic and diastolic 
blood pressures $(\mathrm{p}<0.05)$ [17]. This decrease in blood pressure induced by the consumption of fruits and vegetables (rich in potassium) is explained by the effect of potassium which stimulates the endothelial production of nitric oxide that causes vasodilation and a decrease of blood pressure.

\subsection{Smoking}

Smoking was positively associated with a high risk of HBP. Chen et al. in China, reported that the risk of hypertension was 1.76 times higher who used tobacco compared to those who did not use it $(95 \% \mathrm{CI}=[1.34$; 2.31]) [18]. Abtahi et al. [19], reported that in Iranian teachers, cessation or at least reduction in the amount of smoking would significantly decrease blood pressure. The authors observed that pulse pressure was greater in heavy smokers than those who smoked $<20$ packs year, although the difference was not significant.

\subsection{Physical Activity}

Physical inactivity increases the risk of HBP. This result is similar to those reported by Pessinaba et al., in Senegal in 2013 [20]. Indeed, people who did not participate in at least one moderate daily physical activity were more likely to become hypertensive than those who practiced at least moderate daily physical activity; ( $\mathrm{p}$ $<0.001$ ). Similarly, Stewart de Ramirez et al., reported that in three countries in sub-Saharan Africa, individuals engaged in daily vigorous physical activity showed a reduced risk of developing hypertension with lower blood pressure compared to those who did not practice vigorous physical activity $(p<0.05)$ [17]. The reduction of oxidative stress and psychological stress by physical activity are some of the mechanisms involved in a systematic review to explain the effect of physical activity on blood pressure [21].

\subsection{Overweight and Obesity}

Chen et al. [18] in China, reported that the risk of hypertension is high in obese or overweight people. Previously, in Benin, Houinato et al., reported that the risk of hypertension was 1.99 times higher in obese individuals than in those who were not obese $(\mathrm{p}=0.0001)$ [22]. This increase in blood pressure with excessive weight gain may be related to the release of angiotensinogen by adipocytes. This precursor of angiotensin is involved in a mechanism of vasoconstriction. [23].

The limitations of the present study are that the results can only be generalized to the population of the Aplahoué health district. However, the results reported in this community-based study are useful to design and implement interventions to avert HBP.

\section{Conclusions}

The prevalence of HBP among adults aged 25 to 64 years in the Aplahoué health district was associated with nutritional and lifestyle factors. Interventional studies of promoting healthy diet and lifestyle with the aim of assessing their impact on fighting against HBP and protecting the population from its cardiovascular consequences are needed.

\section{Acknowledgements}

The authors are very grateful to the participants in the study.

\section{REFERENCES}

[1] WHO. Non communicable diseases. Available on https://www.who.int/news-room/fact-sheets/detail/noncom municable-diseases. Cited on 03 August 2019

[2] World Health Organization (WHO). Causes of death. Genève $2008 . \quad$ Available on: http://www.who.int/healthinfo/global burden disease/c od_2008_sources_methods.pdf [Cited on 29/03/2015].

[3] Organisation mondiale de la Santé (OMS). Rapport sur la situation mondiale des maladies non transmissibles 2010: Résumé d'orientation. Genève 2011.

[4] Hashmi SK, Afrid MB, Abbas K, Sajwani RA, Saleheen D, Frossard PM, et al. Factors Associated with Adherence to Anti-Hypertensive Treatment in Pakistan. PLoS One 2007; 2(3): e280.

[5] Kearney PM, Whelton M, Reynolds K, Muntner P, Whelton PK, and He J. Global burden of hypertension: analysis of worldwide data. The Lancet 2005; 365(9455): 217-23.

[6] Houinato DS, Segnon-Agueh J, Djrolo F, Djigbennoude O. Rapport final de l'enquête STEPS au Bénin. Ministère de la Santé. Direction Nationale de la Protection Sanitaire. Programme National de Lutte contre les Maladies Non Transmissibles, Cotonou, 2008.

[7] Elliott WJ. The economic impact of hypertension. The Journal of Clinical Hypertension 2003; 5(3 suppl 2): 3-13.

[8] Union Africaine. Incidence des maladies non transmissibles et des maladies tropicales négligées sur le développement en Afrique: Etat de l'hypertension en Afrique. Conférence des Ministres de la Santé de l'Union Africaine (6e session ordinaire), Addis Abeba, 2013.

[9] Institut National de la Statistique et de l'Analyse Economique. Cahier des villages et quartiers de ville du département du Couffo. Cotonou 2004; 165p

[10] Levesque S, Delisle H, Agueh V. Contribution to the development of a food guide in Benin: linear programming for the optimization of local diets. Public Health Nutr 
$2015 ; 18(4): 622-31$

[11] Programme de consommation contrôlée d'alcool Alcochoix + .Calculer sa consommation [En ligne]. Available on URL: http://www.alcochoix.ch/Dossier/calculer_consommation. html. Cited on 05 April 2015.

[12] WHO/FAO Expert Consultation. "Recommendations for preventing cardiovascular diseases. In: diet, nutrition and the prevention of chronic diseases". WHO Technical Report Series 916, World Health Organization, Geneva 2003.

[13] Abebe SM, Berhane Y, Worku A, Getachew A. Prevalence and Associated Factors of Hypertension: A Crossectional Community Based Study in Northwest Ethiopia. PLoS One 2015; 10(4): e0125210.

[14] Delisle H, Ntandou-Bouzitou G, Agueh V, Roger Sodjinou R, Fayomi B. Urbanisation, nutrition transition and cardiometabolic risk: the Benin study. British Journal of Nutrition 2012; 107: 1534-44.

[15] Ditisheim A, Pechère-Bertschi A, Muradbegovic E, Bochud M, Burnier M. Impact de la consommation de sel sur la santé : les croyances de la population suisse. Rev Med Suisse 2013; 397: 1613-16.

[16] Cooperative Research Group (INTERSALT): an international study of electrolyte excretion and blood pressure. Results for 24 hour urinary sodium and potassium excretion. B Med J. 1988; 297: 319-28.

[17] Stewart de Ramirez S, Enquobahrie DA, Nyadzi G, Mjungu D, Magombo F, Ramirez M, and al. Prevalence and correlates of hypertension: a cross-sectional study among rural populations in sub-Saharan Africa. Journal of Human Hypertension 2010; 24: 786-95.

[18] Chen L, Zong Y, Wei T, Sheng X, Shen W, Li J, et al. Prevalence, awareness, medication, control, and risk factors associated with hypertension in $\mathrm{Yi}$ ethnic group aged 50 years and over in rural China: the Yunnan minority eye study. BMC Public Health 2015; 15: 383.

[19] Abtahi F, Kianpour Z, Zibaeenezhad MJ, Naghshzan A, Heydari ST , Babaie Beigi MA, et al.. Correlation between cigarette smoking and blood pressure and pulse pressure among teachers residing in Shiraz, Southern Iran. Iran Cardiovasc Res J 2011;5(3):97-102

[20] Pessinaba S, Mbaye A, Yabeta GAD, Kane A, Ndao CT, Ndiaye MB. Prevalence and determinants of hypertension and associated cardiovascular risk factors: data from a population-based, cross-sectional survey in Saint Louis, Senegal. Cardiovascular Journal of Africa 2013; 24(5):180-83.

[21] Diaz KM, Shimbo D. Physical Activity and the Prevention of Hypertension. Curr Hypertens Rep. 2013; 15(6): 659-668. doi:10.1007/s11906-013-0386-8

[22] Houinato DS, Gbary AR, Houehanou YC, Djrolo F, Amoussou M, Segnon-Agueh J, et al. Prévalence de l'hypertension artérielle et facteurs de risque associés en population générale au Bénin. Revue d'Epidémiologie et de Santé Publique 2012; 60(2): 95-102.

[23] Fezeu L, Kengne AP, Balkau B, Awah PK, Mbanya JC. Ten-year change in blood pressure levels and prevalence of hypertension in urban and rural Cameroon. J Epidemiol Community Health 2010; 64: 360-65. 